\title{
Pharma expats: a Q\&A with two who made the move to a contract research organization
}

\author{
lan Waddell*,1 \& Chris Hill ${ }^{1}$ \\ ${ }^{1}$ Charles River Laboratories, Chesterford Research Park, Saffron Walden CB10 1XL, UK \\ *Author for correspondence: lan.Waddell@crl.com
}

First draft submitted: 10 April 2019; Accepted for publication: 10 April 2019; Published online: 18 June 2019

Keywords: chemists $\bullet$ contract research organizations $\bullet$ drug discovery $\bullet$ industry insiders $\bullet$ pharmaceutical industry

Are you curious about what would make two former pharma employees switch to working for a contract research organization (CRO)? In this Q\&A, Ian Waddell and Chris Hill discuss their experiences making the change from client to contractor for Charles River Labs. I Waddell is passionate about raising visibility of the reproducibility issue in drug discovery and science in general. He obtained his $\mathrm{PhD}$ in molecular medicine at the University of Dundee in Scotland, and completed postdoctoral fellowships in the US. I Waddell started his career at Dundee, moved to AstraZeneca and later returned to academia as the head of biology drug discovery with the Cancer Research UK (CRUK) Manchester Institute. In a career spanning over 30 years, C Hill has led drug discovery teams at some of the most storied pharmaceutical companies in the world, including Roche, Organon, Schering-Plough and Merck. 'Companies need CRO partners for a variety of reasons,' said Hill. 'Capacity and capability are two of those, of course. But the third reason, equally important, is about injecting diversity of thought into an organization's programs.'

\section{You have both had prestigious careers to date, why did you decide to move into the CRO sector at this time?}

I Waddell: I was frustrated by the fact that the charity I worked for kept changing directions when it came to drug discovery, and I wanted to work for a company that could do end-to-end drug discovery.

Also, in recent years, the role of teaching the next generation of drug hunters has fallen largely to CROs. This is reflected by the fact that many of our staff who decided it was time for something new in their career would move off to join biotechs and large pharma, whereas 10-15 years ago the flow would have been very much in the other direction. I do not see this as a bad thing, it is just an industry moving on.

C Hill: After spending 30 years in large pharma organizations I felt that I needed a change, and I was keen to learn about wider business elements of research. Like many others, I chose to set up my own consulting company, and enjoyed a more balanced view on work for a year or so. However, it soon dawned upon me that I missed the 'cut and thrust' of being part of a dynamic discovery research environment with a strong team of creative and collaborative colleagues.

As large pharma organizations have consolidated and outsourced more work, it became apparent to me that the training ground for the drug hunters of the future has shifted away from big pharma.

\section{What did you expect to find when you joined a CRO?}

I Waddell: In my previous roles, I worked with two of the legacy Early Discovery organizations, so I thought I had a fairly good idea of the capabilities of a CRO. However, if I am honest, I thought the staff at a CRO would be fairly junior and relatively inexperienced. I think this was borne out from my pharma mentality where we thought of CROs in terms of gaining extra capacity and not really in terms of new skills and expertise. That thinking was based around 'we are the best, and if a CRO can do it for less it must be because they employ less experienced staff.'

C Hill: I had visited Charles River with my former company and was impressed with the quality of the chemists that I met. At that time, I was interested in potential partnerships with CROs that had chemists who could strongly 
contribute to solving the toughest medicinal chemistry problems, so I had high expectations of the quality of the people.

\section{Have those expectations turned out to be true?}

I Waddell: In terms of the capabilities at Early Discovery, my expectations have been far surpassed, both in terms of the breadth of drug discovery knowledge and their skills across many therapeutic areas. My views about the quality of the staff were wildly inaccurate, and I have been massively impressed by the skills and experience of my staff. Of course, what I had missed was that CROs had benefited from the demise of the UK Pharma industry by recruiting very experienced staff from a broad range of companies. I think that this mix of experiences and diverse ways of thinking really helps us, and now we are passing on that breadth of knowledge to the next generation of drug hunters.

\section{What has surprised you most about working at a CRO?}

I Waddell: At a personal level, I was surprised by the sheer pace, volume and variety of the work that the early discovery function undertakes.

C Hill: I challenge anyone from big pharma to spend 3 months in our business to fully understand what a dynamic environment looks like! It was the biggest change that I found when I moved to this environment. Everything is done at a fast pace, and quality is paramount. Continuous improvement is a driver in every part of the business, and the scientific challenges and problems are the same as everywhere else.

\section{What new technologies do you find the most exciting or promising?}

C Hill: Capture Compound Mass Spectrometry is a powerful technology for deconvoluting disease-relevant phenotypic assays to identify the molecular target of interest. By using this approach, you can have more confidence in the molecular target that you have selected. The same Capture Compound Mass Spectrometry technology can also be used to identify the molecular mechanism of any undesirable effects seen when a project is in lead optimization. Safety is paramount for any efficacious drug, so having the ability to optimize away from off target activities in a timely way is extremely valuable.

Artificial intelligence is another exciting area. The value of any predictive capability is that we are better able to design the right compounds faster. This can potentially reduce the number of design cycles for wet laboratory work and subsequently speed up the process.

I Waddell: I am really excited by our partnership with Distributed Bio. Partly because it represents a part of the jigsaw that was missing before, but also because I am really excited by the technology. With 76 billion antibodies and computationally optimized complementarity-determining region fitness, the technology allows hits against any epitope with drug-worthy scaffolds and superior encoded developability.

\section{How could drug developers \& CROs help each other even more, from your perspective?}

I Waddell: Despite working for more than 18 months at a CRO, I still very much think of myself as a drug hunter, and my biggest thrill is working with my chemistry and ADME colleagues on an integrated project. Many of our clients are biotechs and mid-sized pharma, and the simplest way that we could help each other more would be to engage in discussions about projects earlier. There are very few CROs who can say that they have delivered 80 preclinical candidates to their clients, and that can only be said about a company with deep and broad drug discovery experience.

C Hill: I think that there is still a widespread view of CROs as just additional capacity rather than as an opportunity to bring something different to the team. In my view, it is really important that we learn from one another. One of the real potential strengths of a partnership between a drug discovery organization and a CRO is the diversity of thought and problem-solving capabilities that both partners can contribute to a project. I believe that the most successful projects generally result from a mindset of an equal partnership, where all ideas are embraced and prioritized together. 
No writing assistance was utilized in the production of this manuscript.

\section{Disclaimer}

The opinions expressed in this interview are those of the interviewee and do not necessarily reflect the views of Future Science Ltd. This article is being published concurrently elsewhere. The articles are identical except for minor stylistic and spelling changes in keeping with each journal's style.

\section{Open access}

This work is licensed under the Attribution-NonCommercial-NoDerivatives 4.0 Unported License. To view a copy of this license, visit http://creativecommons.org/licenses/by-nc-nd/4.0/ 